\title{
In vitro Antimicrobial Activity of Chlorquinaldol against Microorganisms Responsible for Skin and Soft Tissue Infections: Comparative Evaluation with Gentamicin and Fusidic Acid
}

\author{
Monica Bortolin ${ }^{1}$, Alessandro Bidossi ${ }^{1}$, Elena De Vecchi ${ }^{1}$, Maura Avveniente ${ }^{1}$ and \\ Lorenzo Drago ${ }^{1,2 *}$
}

${ }^{1}$ Laboratory of Clinical Chemistry and Microbiology, IRCCS Galeazzi Orthopaedic Institute, Milan, Italy, ${ }^{2}$ Laboratory of Clinical Microbiology, Department of Biomedical Sciences for Health, University of Milan, Milan, Italy

\section{OPEN ACCESS}

Edited by:

Octavio Luiz Franco,

Universidade Católica de Brasilia,

Brazil

Reviewed by:

Osmar Nascimento Silva Universidade Católica Dom Bosco,

César de la Fuente,

Massachusetts Institute of

Technology, United States

*Correspondence:

Lorenzo Drago

lorenzo.drago@unimi.it

Specialty section

This article was submitted to

Antimicrobials, Resistance and

Chemotherapy,

a section of the journal

Frontiers in Microbiology

Received: 15 March 2017

Accepted: 23 May 2017

Published: 08 June 2017

Citation:

Bortolin M, Bidossi A, De Vecchi E.

Avveniente M and Drago L (2017) In vitro Antimicrobial Activity of

Chlorquinaldol against

Microorganisms Responsible for Skin and Soft Tissue Infections:

Comparative Evaluation with

Gentamicin and Fusidic Acid.

Front. Microbiol. 8:1039.

doi: 10.3389/fmich.2017.01039
Skin and soft tissue infections (SSTIS) are a major therapeutic challenge for clinicians. The emergence of pathogens with decreased susceptibility to available therapies has become an emerging problem often associated with treatment failure. Hence, there is an urgent need for novel broad-spectrum antimicrobial agents. The purpose of this study was to assess the feasibility of chlorquinaldol as an alternative approach to currently used topical antibiotics for the treatment of skin and soft tissue infections. The activity of chlorquinaldol was investigated against a collection of bacterial isolates responsible for skin infections, including strains resistant to fusidic acid and gentamicin. After determination of MIC and $\mathrm{MBC}$, time-kill experiments were carried out by counting colonies grown after 0 , $3,6,9,24$, and $48 \mathrm{~h}$ of incubation with concentrations equal to $1 / 4 \times, 1 / 2 \times, 1 \times, 2 \times$, and $4 \times$ MIC of chlorquinaldol, gentamicin, or fusidic acid. Staphylococci resulted the Gram-positives most sensitive to chlorquinaldol, with MIC-values ranging from 0.016 to $0.5 \mathrm{mg} / \mathrm{L}$. A lower activity was observed against Gram-negative bacteria, with $77 \%$ of the isolates being inhibited at concentrations ranging from 128 to $512 \mathrm{mg} / \mathrm{L}$. Generally, in time-kill studies, chlorquinaldol showed a bactericidal activity at the higher concentrations (2x, 4x MIC) after 24-48 h of incubation. In conclusion, chlorquinaldol may represent a valuable alternative to conventional topical antibiotics for the treatment of skin and soft tissue infections.

Keywords: chlorquinaldol, gentamicin, fusidic acid, skin infections, time-kill curves, minimum inhibitory concentration, minimum bactericidal concentration

\section{INTRODUCTION}

Skin and soft tissue infections (SSTIs) are commonly occurring diseases with a wide-range of clinical manifestations varying from minor superficial to life-threatening infections (Ray et al., 2013). They may range from "simple uncomplicated" infections, such as erysipelas, cellulitis, simple abscesses, furuncles, and wound infections, to deeper "complicated" infections, such as necrotizing fasciitis, myositis, and gas gangrene. 
The etiology of SSTIs is dominated by Staphylococcus aureus, but other common isolates include $\beta$-haemolytic streptococci, enterococci, Enterobacteriaceae, anaerobes, and Pseudomonas aeruginosa (Lipsky et al., 2007).

SSTIs are caused by microorganisms multiplication, leading to prolonged inflammatory response, delays in collagen synthesis and epithelialization, and tissue damage. Even though careful attention is paid to patients with acute infections, treatment often fails in chronic ones, where healing is hampered by the presence of bacterial biofilm (Bjarnsholt, 2013).

Despite high rate of morbidity and significant burden to the health care system, the management of skin lesions is still far from being completely effective and novel therapies are urgently needed (van Koppen and Hartmann, 2015).

Topical antibiotics are key components in the management of skin lesions. However, cases of sensitization are not uncommon (Bonamonte et al., 2014). Poor penetration and variable antimicrobial concentration can lead to resistance and scarce efficacy (Esposito et al., 2016). The emergence of pathogens with decreased susceptibility to available antibiotics has become an emerging clinical problem often associated with treatment failure, even with topical drugs of choice, such as fusidic acid (Heng et al., 2013). Fusidic acid monotherapy, in particular as topical preparation, is frequently used in dermatology and has been linked to the emergence of fusidic acid resistance in MSSA and MRSA (Heng et al., 2013).

Hence, there is an urgent need for novel broad-spectrum antimicrobial agents, which can be used to successfully treat cutaneous infections and overcome antibiotic resistance.

Chlorquinaldol, or hydroxydichloroquinaldine (5,7-dichloro2-methyl-8-quinolinol), is a derivative of 8-hydroxyquinoline which is usually administered topically for the treatment of skin infections, alone or in combination with diflucortolone valerate (Maeder et al., 1983; Hoppe, 1988; Corrihons et al., 1991). In few past studies, chlorquinaldol has proven to be effective in vitro against a wide variety of fungi and a few bacterial species, and in vivo against a series of cutaneous conditions involving microbial infections or allergic skin conditions for which a supplementary anti-infective treatment, for prophylaxis or therapy, was indicated (Littman, 1955; Robinson and Hollander, 1956; Mann et al., 1960; Regös et al., 1979; Meyer-Rohn and Puschmann, 1980; Maeder et al., 1983; Kolev et al., 1987; Hoppe,
1988; Corrihons et al., 1991; Sikorski et al., 1992; Zlatkov et al., 1996). Despite these promising observations, no further studies about the antimicrobial activity of chlorquinaldol were performed and recent investigations are lacking.

The purpose of this study was to assess the feasibility of chlorquinaldol as a potential alternative approach to currently used topically applied antibiotics for the treatment of skin infections, including fusidic acid and gentamicin.

\section{MATERIALS AND METHODS}

\section{Microorganisms}

Clinically relevant strains isolated from SSTIs at the Laboratory of IRCCS Galeazzi Orthopedic Institute were used. In particular, methicillin-resistant S. aureus (MRSA, $n=9$ ), methicillin-susceptible $S$. aureus (MSSA, $n=8$ ), methicillin-resistant Staphylococcus epidermidis (MRSE, $n$ $=13)$, Streptococcus pyogenes $(n=6)$, Enterococcus faecalis $(n=$ $13)$, Propionibacterium acnes $(n=10)$, Proteus mirabilis $(n=11)$, $P$. aeruginosa $(n=12)$, Escherichia coli $(n=12)$, and Enterobacter spp. $(n=12)$ were used. Identification of the isolates was carried out on a Vitek2 Compact (BioMerieux, Marcy L'Etoile, France) and further confirmed by pyrosequencing (PSQ96RA, Diatech, Jesi, Italy).

TABLE 2 | MIC and MBC ranges for Gram-negative bacterial strains.

\begin{tabular}{|c|c|c|c|c|}
\hline & \multicolumn{2}{|c|}{ Chlorquinaldol } & \multicolumn{2}{|c|}{ Gentamicin } \\
\hline & MIC (mg/L) & MBC (mg/L) & MIC (mg/L) & $\mathrm{MBC}(\mathrm{mg} / \mathrm{L})$ \\
\hline \multicolumn{5}{|c|}{ GENTAMICIN-SUSCEPTIBLE STRAINS (MIC $\leq 4 \mathrm{mg} / \mathrm{L}$ ) } \\
\hline E. coli & $8-128$ & $>512$ & $2-4$ & $4-8$ \\
\hline Enterobacter spp. & $128-512$ & $>512$ & $2-4$ & $2-8$ \\
\hline P. mirabilis & 512 & $>512$ & 4 & 4 \\
\hline$P$. aeruginosa & $128-512$ & $512->512$ & $2-4$ & $4-32$ \\
\hline \multicolumn{5}{|c|}{ GENTAMICIN-RESISTANT STRAINS (MIC > 4 mg/L) } \\
\hline E. coli & $8-512$ & $>512$ & $8->512$ & $8->512$ \\
\hline Enterobacter spp. & $128-512$ & $>512$ & $64->512$ & $64->512$ \\
\hline P. mirabilis & $32-512$ & $256->512$ & $8->512$ & $16->512$ \\
\hline P. aeruginosa & $32-256$ & $128->512$ & $128->512$ & $256->512$ \\
\hline
\end{tabular}

TABLE 1 | MIC and MBC ranges for Gram-positive bacterial strains.

\begin{tabular}{|c|c|c|c|c|c|c|}
\hline & \multicolumn{2}{|c|}{ Chlorquinaldol } & \multicolumn{2}{|c|}{ Gentamicin } & \multicolumn{2}{|c|}{ Fusidic acid } \\
\hline MSSA & $0.25-0.5$ & $1-4$ & $2->512$ & $2->512$ & $0.016-2$ & $0.125-2$ \\
\hline MRSE & $0.016-0.5$ & $0.032-4$ & $0.25-512$ & $0.25-128$ & $<0.016-8$ & $<0.016-64$ \\
\hline E. faecalis & $0.25-2$ & $0.25-2$ & NT & NT & $4-16$ & $16-512$ \\
\hline P. acnes & $16-32$ & $32-512$ & $>512$ & $>512$ & $0.125-0.5$ & $2-16$ \\
\hline
\end{tabular}

NT, not tested because of intrinsic resistance to gentamicin. 
TABLE 3 | MIC distributions (mg/L).

\begin{tabular}{|c|c|c|c|c|c|c|c|c|c|c|c|c|c|c|c|c|c|c|}
\hline & $<0.016$ & 0.016 & 0.032 & 0.064 & 0.125 & 0.25 & 0.5 & 1 & 2 & 4 & 8 & 16 & 32 & 64 & 128 & 256 & 512 & $>512$ \\
\hline \multicolumn{19}{|c|}{ CHLORQUINALDOL } \\
\hline MRSA & & & & & 1 & 8 & & & & & & & & & & & & \\
\hline MSSA & & & & & & 5 & 3 & & & & & & & & & & & \\
\hline MRSE & & 1 & 1 & 1 & 4 & 4 & 2 & & & & & & & & & & & \\
\hline E. faecalis & & & & & & 1 & 2 & 9 & 1 & & & & & & & & & \\
\hline E. coli & & & & & & & & & & & 9 & & & & 1 & 1 & 1 & \\
\hline Enterobacter spp. & & & & & & & & & & & & & & & 3 & 6 & 3 & \\
\hline P. mirabilis & & & & & & & & & & & & & 1 & & & 5 & 5 & \\
\hline$P$. aeruginosa & & & & & & & & & & & & & 2 & & 5 & 4 & 1 & \\
\hline \multicolumn{19}{|l|}{ GENTAMICIN } \\
\hline P. acnes & & & & & & & & & & & & & & & & & & 10 \\
\hline E. coli & & & & & & & & & 1 & 5 & 1 & 1 & & & & 1 & 2 & 1 \\
\hline Enterobacter spp. & & & & & & & & & 4 & 4 & & & & 1 & & & 1 & 2 \\
\hline P. mirabilis & & & & & & & & & & 1 & 1 & & & 1 & 2 & 2 & 1 & 3 \\
\hline$P$. aeruginosa & & & & & & & & & 1 & 2 & & & & & 1 & & 2 & 6 \\
\hline \multicolumn{19}{|l|}{ FUSIDIC ACID } \\
\hline MRSA & & 5 & 4 & & & & & & & & & & & & & & & \\
\hline MSSA & & 1 & 6 & & & & & & 1 & & & & & & & & & \\
\hline MRSE & 3 & 1 & 2 & & 1 & & 1 & & 2 & 2 & 1 & & & & & & & \\
\hline E. faecalis & & & & & & & & & & 1 & 6 & 6 & & & & & & \\
\hline S. pyogenes & & & & & & & & & & 4 & 2 & & & & & & & \\
\hline
\end{tabular}

\section{Drugs}

Stock solutions of chlorquinaldol (MedChemtronica AB, Stockholm, Sweden), fusidic acid (Cayman Chemical, Ann Arbor, MI, USA), and gentamicin (MP Biomedicals, Santa Ana, CA, USA) were prepared in $95 \%$ ethanol (chlorquinaldol) or sterile water (fusidic acid and gentamicin) at concentrations of $5,000 \mathrm{mg} / \mathrm{L}$ and stored in aliquots at $-20^{\circ} \mathrm{C}$ until use.

\section{Evaluation of Minimum Inhibitory Concentration (MIC) and Minimum Bactericidal Concentration (MBC)}

The bacteriostatic and bactericidal properties of chlorquinaldol and its spectrum of activity were evaluated in comparison with gentamicin and fusidic acid.

The antimicrobial activity was assessed by determining the $\mathrm{MIC}$ and the MBC-values against the microbial strains described above. The MIC was determined by broth microdilution method, in accordance with EUCAST standard ${ }^{1}$. Briefly, a suspension in growth medium (Brain heart infusion broth, Biomérieux, Marci

${ }^{1}$ http://www.eucast.org/fileadmin/src/media/PDFs/EUCAST_files/MIC_testing/ Edis5.1_broth_dilution.pdf
l'Etoile, France) was prepared for each bacterial strain with an optical density equal to $0.5 \mathrm{McF}$ arland $\left(1.5 \times 10^{8} \mathrm{CFU} / \mathrm{ml}\right)$. For $P$. acnes broth was supplemented with $3 \%$ of defibrinated sheep blood (Liofilchem, Roseto degli Abruzzi, Italy). After obtaining a concentration of $10^{5} \mathrm{CFU} / \mathrm{ml}$ using appropriate dilutions, each suspension was inoculated in a 96-wells microtiter plate containing a serial 2-fold dilution of chlorquinaldol, fusidic acid, or gentamicin. MIC-values, corresponding to the lowest concentration exhibiting no visible bacterial growth, were read after $24 \mathrm{~h}$ of incubation at proper conditions (except for $P$. acnes that required $48 \mathrm{~h}$ ). The $\mathrm{MBC}$ was determined by plating $10 \mu \mathrm{l}$ from each well showing no turbidity onto agar plates. After incubation at proper conditions, MBC was read as the lowest concentration able to kill $99.9 \%$ of the initial inoculum.

\section{Time-Kill Curves}

Killing curves were performed against one representative strains of each species described above. Briefly, a suspension in growth medium was prepared for each bacterial strain with an optical density equal to $0.5 \mathrm{McF}$ arland $\left(1.5 \times 10^{8} \mathrm{CFU} / \mathrm{mL}\right)$. An aliquot was inoculated into test tubes containing $2 \mathrm{ml}$ of growth medium alone (growth control) or containing each testing substance (see above) at different concentrations $(1 / 4 \times, 1 / 2 \times .1 \times, 2 \times$, and 
TABLE 4 | MBC distributions (mg/L).

\begin{tabular}{|c|c|c|c|c|c|c|c|c|c|c|c|c|c|c|c|c|c|c|}
\hline & $<0.016$ & 0.016 & 0.032 & 0.064 & 0.125 & 0.25 & 0.5 & 1 & 2 & 4 & 8 & 16 & 32 & 64 & 128 & 256 & 512 & $>512$ \\
\hline \multicolumn{19}{|c|}{ CHLORQUINALDOL } \\
\hline MRSA & & & & & 2 & 2 & 1 & & 3 & 1 & & & & & & & & \\
\hline MRSE & & & 2 & & 1 & 3 & 1 & 2 & 3 & 1 & & & & & & & & \\
\hline E. faecalis & & & & & & 1 & 1 & 7 & 4 & & & & & & & & & \\
\hline E. coli & & & & & & & & & & & & & & & & & & 12 \\
\hline$P$. aeruginosa & & & & & & & & & & & & & & & 1 & 1 & 5 & 5 \\
\hline Enterobacter spp. & & & & & & & & & & & & & & & & & & 12 \\
\hline P. mirabilis & & & & & & & & & & & & & & & & 1 & 3 & 7 \\
\hline \multicolumn{19}{|l|}{ GENTAMICIN } \\
\hline P. acnes & & & & & & & & & & & & & & & & & & 10 \\
\hline E. coli & & & & & & & & & & 4 & 3 & 1 & & & & 1 & 1 & 2 \\
\hline$P$. aeruginosa & & & & & & & & & & 1 & 1 & & 1 & & & 1 & 2 & 6 \\
\hline Enterobacter spp. & & & & & & & & & 4 & 3 & 1 & & & 1 & & & & 3 \\
\hline P. mirabilis & & & & & & & & & & 1 & & 1 & & & 1 & & 5 & 3 \\
\hline \multicolumn{19}{|l|}{ FUSIDIC ACID } \\
\hline MRSA & & & & & 2 & 1 & 1 & 2 & 3 & & & & & & & & & \\
\hline MSSA & & & & & 2 & 1 & 1 & 1 & 3 & & & & & & & & & \\
\hline MRSE & 1 & & & & 2 & & 3 & 2 & & 1 & 1 & & 2 & 1 & & & & \\
\hline E. faecalis & & & & & & & & & & & & 1 & & & & 5 & 7 & \\
\hline S. pyogenes & & & & & & & & & & & & 3 & 1 & 2 & & & & \\
\hline
\end{tabular}

$4 \times$ MIC). Final concentration of bacteria was $5 \times 10^{5}-5 \times 10^{6}$ $\mathrm{CFU} / \mathrm{mL}$. Tubes were incubated at $37^{\circ} \mathrm{C}$ in proper conditions. Microbial counts were performed after $0,3,6,9,24$, and $48 \mathrm{~h}$ of incubation by plating $0.1 \mathrm{~mL}$ of a proper dilution of bacterial suspension onto agar plates. Results were expressed as $\log _{10}$ $(\mathrm{CFU} / \mathrm{mL})$. The limit of count detection was $200 \mathrm{CFU} / \mathrm{mL}$. Bactericidal activity was defined as a $3 \log _{10}$ decrease in CFU/mL (99.9\% kill) of the initial inoculum. Bacteriostatic activity was defined as $<99.9 \%$ kill.

Time-kill curves of gentamicin and fusidic acid were performed only on strains classified as susceptible according to EUCAST breakpoint ${ }^{2}$.

\section{RESULTS}

\section{Chlorquinaldol, Fusidic Acid, and Gentamicin Antibacterial Activity}

Tables 1, 2 show MIC and MBC ranges, while Tables 3, 4 show distributions of MIC and MBC-values for chlorquinaldol, fusidic acid, and gentamicin tested against Gram-positive and Gramnegative strains.

${ }^{2} \mathrm{http} / / /$ www.eucast.org/clinical_breakpoints/

\section{Gram-Positive Bacterial Strains}

Among Gram positives, staphylococci resulted the most sensitive cocci to chlorquinaldol, which was able to inhibit bacterial growth at concentrations ranging between 0.016 and $0.5 \mathrm{mg} / \mathrm{L}$. MBC-values were highly variable: in $47 \%$ of cases they were equal or 2-fold the MIC, in 37\% 4-8-folds the MIC, and in the remaining $16 \%$ they were $16-32$-folds the MIC. Chlorquinaldol was effective at low concentrations against $E$. faecalis, presenting $\mathrm{MIC}$ and MBC-values ranging from 0.25 to $2 \mathrm{mg} / \mathrm{L}$. MBCvalues were always close to MIC-values (equal or 2-folds higher than the MIC). Modest inhibitory activity was observed against S. pyogenes and P. acnes.

All staphylococci with the exception of five MRSE strains resulted resistant to gentamicin. All $P$. acnes presented MIC and MBC-values higher than $512 \mathrm{mg} / \mathrm{L}$. Staphylococci displayed the highest variability among the tested strains with MIC and $\mathrm{MBC}$-values ranging from 0.25 to $1,024 \mathrm{mg} / \mathrm{L}$.

All S. aureus strains were susceptible to fusidic acid, presenting MIC-values varying from 0.016 to $0.032 \mathrm{mg} / \mathrm{L}$, with the exception of one MSSA isolate (MIC $2 \mathrm{mg} / \mathrm{L}$ ). Eight strains of S. epidermidis were susceptible to fusidic acid, while five strains were found to be resistant. Propionibacteria were inhibited by low concentrations of fusidic acid, while higher MIC-values were observed for E. faecalis and S. pyogenes. Generally, MBC of 
fusidic acid were 4-128 times higher than the corresponding MIC.

\section{Gram-Negative Bacterial Strains}

Gram-negative strains revealed a high heterogeneity in distribution of gentamicin resistance, so that susceptible and resistant strains are reported separately in Table 2. Strains with a MIC-value higher than $4 \mathrm{mg} / \mathrm{L}$ were $50 \%$ of $E$. coli, $75 \%$ of P. aeruginosa, $33 \%$ of Enterobacter spp., and $81 \%$ of $P$. mirabilis. $\mathrm{MBC}$-values were close to MIC-values (equal or two times higher than the MIC), except for one P. aeruginosa strain (MIC $2 \mathrm{mg} / \mathrm{L}$, MBC $32 \mathrm{mg} / \mathrm{L}$ ).

Chlorquinaldol spectrum of activity revealed a lower activity against Gram-negative bacilli in respect to the Gram-positive tested bacteria, with $77 \%$ of the isolates being inhibited at concentrations ranging from 128 to $512 \mathrm{mg} / \mathrm{L}$ and $23 \%$ being inhibited at concentrations $\leq 32 \mathrm{mg} / \mathrm{L}$. Of the latter group, 9 E. coli isolates showed a MIC-value of $8 \mathrm{mg} / \mathrm{L}$, while $1 P$. mirabilis and $2 P$. aeruginosa isolates showed a MIC-value of $32 \mathrm{mg} / \mathrm{L}$. MBC-values were $\geq 512 \mathrm{mg} / \mathrm{L}$ for $77 \%$ of tested strains (Table 4).

\section{Time-Kill Curves}

Figures 1-6 show the pattern of growth and kill by antibiotics of the various microbial species tested, at different concentrations of each of the tested antibiotics.

\section{Gram-Positive Bacterial Strains}

Time-kill curves for Gram-positive strains are reported in Figures 1-4. Chlorquinaldol showed bactericidal activity, as defined by a $3 \log _{10}$ reduction in viable count, after 48 $\mathrm{h}$ for $S$. epidermidis $(4 \times \mathrm{MIC}), \mathrm{MSSA}(4 \times \mathrm{MIC}), \mathrm{MRSA}$ ( $4 \times$ MIC), and E. faecalis $(4 \times$ and $2 \times$ MIC), and after $24 \mathrm{~h}$ and $48 \mathrm{~h}$ for $S$. pyogenes ( $4 \times$ and $2 \times \mathrm{MIC}) .2$ $\log _{10}$ reductions were observed for MRSA $(2 \times$ MIC), $P$. acnes $(4 \times \mathrm{MIC})$, and E. faecalis $(1 \times \mathrm{MIC})$ after $48 \mathrm{~h}$ of exposure. Gentamicin $(4 \times$ and $2 \times$ MIC concentrations) was bactericidal against $S$. epidermidis after 24 and 48 h. Fusidic acid was essentially bacteriostatic against staphylococci and P. acnes.

\section{Gram-Negative Bacterial Strains}

Time-kill curves for Gram-negative strains are reported in Figures 5, 6. Chlorquinaldol displayed a bactericidal activity against $P$. aeruginosa after $48 \mathrm{~h}$ exposure $(4 \times \mathrm{MIC})$ and against P. mirabilis after $24 \mathrm{~h}(4 \times \mathrm{MIC})$ and $48 \mathrm{~h}(2 \times$ and $4 \times \mathrm{MIC})$. $2 \log _{10}$ reductions were observed for E. coli $(4 \times \mathrm{MIC})$ and E. cloacae $(4 \times \mathrm{MIC})$ after $48 \mathrm{~h}$ of exposure, and for P. mirabilis after $24 \mathrm{~h}(2 \times \mathrm{MIC})$. Gentamicin was bactericidal against $E$. coli after $6 \mathrm{~h}(4 \times \mathrm{MIC})$ and $9 \mathrm{~h}(2 \times \mathrm{MIC})$, against $E$. cloacae after $6 \mathrm{~h}$ $(2 \times$ and $4 \times \mathrm{MIC})$ and $9 \mathrm{~h}(1 \times \mathrm{MIC})$, and against $P$. aeruginosa after $6 \mathrm{~h}(4 \times \mathrm{MIC})$ and $9 \mathrm{~h}(2 \times \mathrm{MIC})$.

\section{DISCUSSION}

SSTIs are common in both community and hospital settings. They present with a wide clinical spectrum, from superficial self-limiting infections to deep and potentially life-threatening

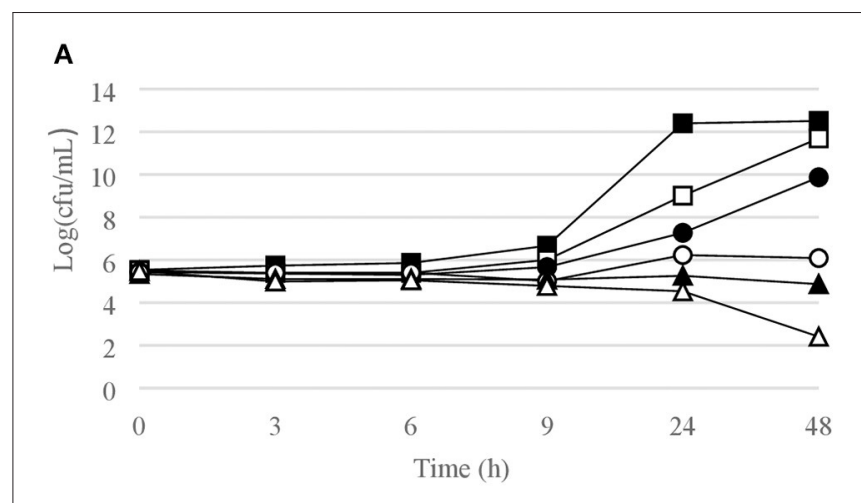

B

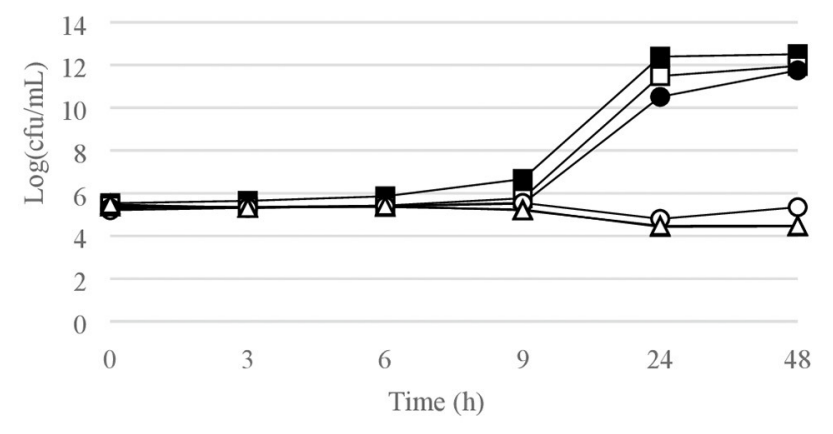

C

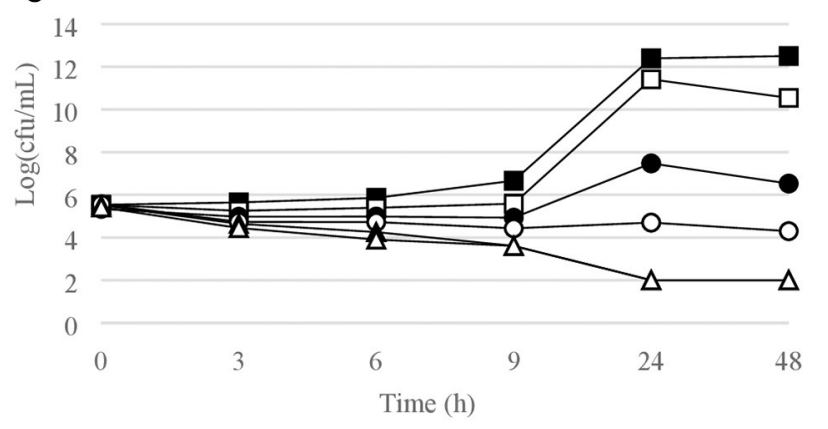

FIGURE 1 | Time-kill curves for S. epidermidis. (A) chlorquinaldol; (B) fusidic acid; (C) gentamicin. Filled square, control; open square, $1 / 4 \times$ MIC; filled circle, $1 / 2 \times \mathrm{MIC}$; open circle, $1 \times \mathrm{MIC}$; filled triangle, $2 \times \mathrm{MIC}$; open triangle, $4 \times \mathrm{MIC}$.

ones (Ray et al., 2013). Gram-positive organisms, such as staphylococci and $S$. pyogenes, are the dominant organisms isolated in the acute infectious process, whereas Gram-negative organisms are more often seen in chronic or postoperative wounds (Cardona and Wilson, 2015).

In the recent years, there has been an increased incidence in SSTIs as a consequence of a number of factors, such as aging of the general population, higher incidence of immunocompromised patients and emergence of multidrugresistant pathogens.

Topical antibiotics are key components in the management of SSTIs, but the emergence of pathogens with decreased susceptibility to available therapies has become an emerging clinical problem often associated with treatment 

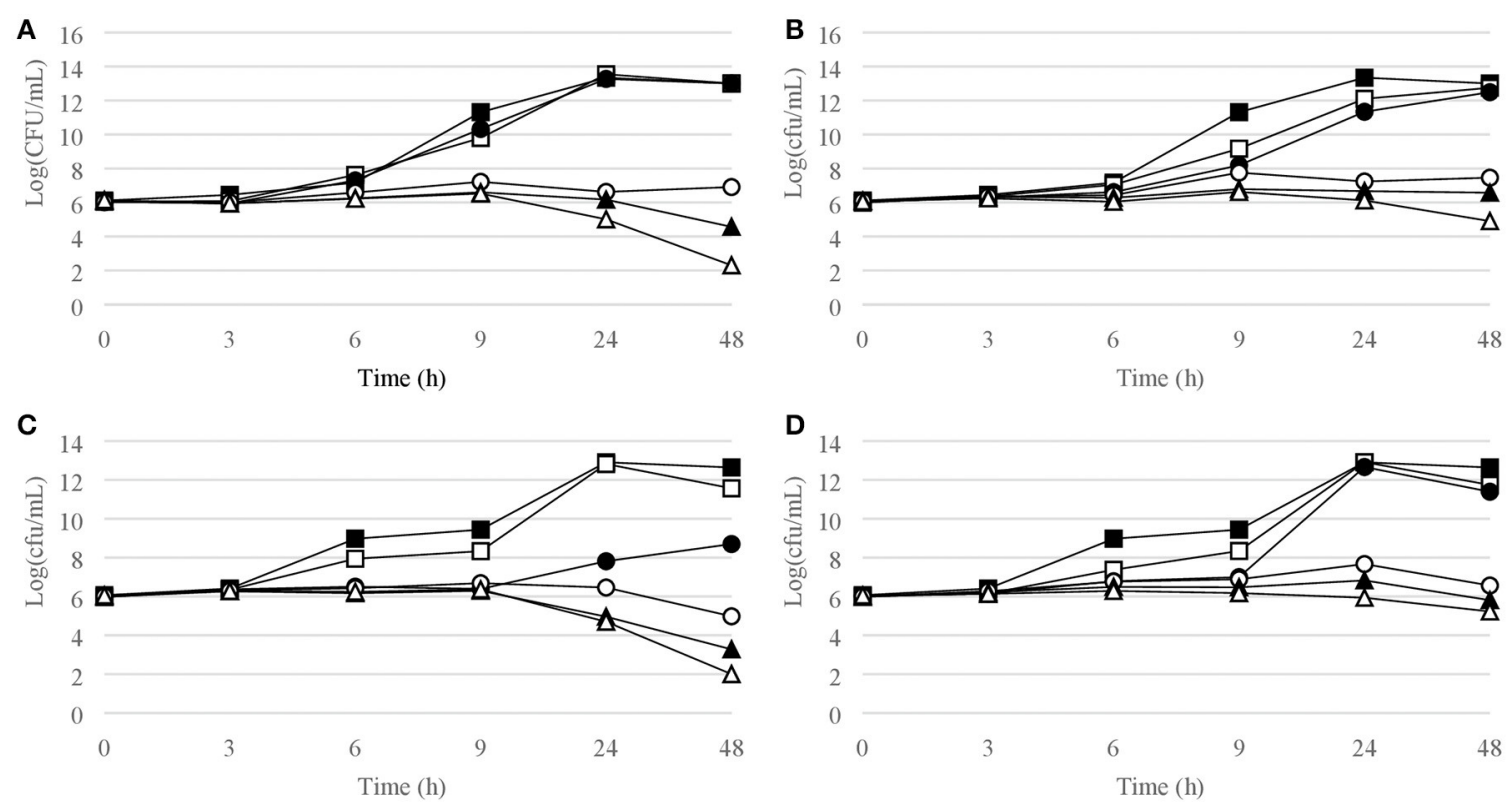

FIGURE 2 | Time-kill curves for S. aureus. (A) chlorquinaldol, MSSA; (B) fusidic acid, MSSA; (C) chlorquinaldol, MRSA; (D) fusidic acid, MRSA. Filled square, control; open square, $1 / 4 \times$ MIC; filled circle, $1 / 2 \times$ MIC; open circle, $1 \times$ MIC; filled triangle, $2 \times \mathrm{MIC}$; open triangle, $4 \times \mathrm{MIC}$.

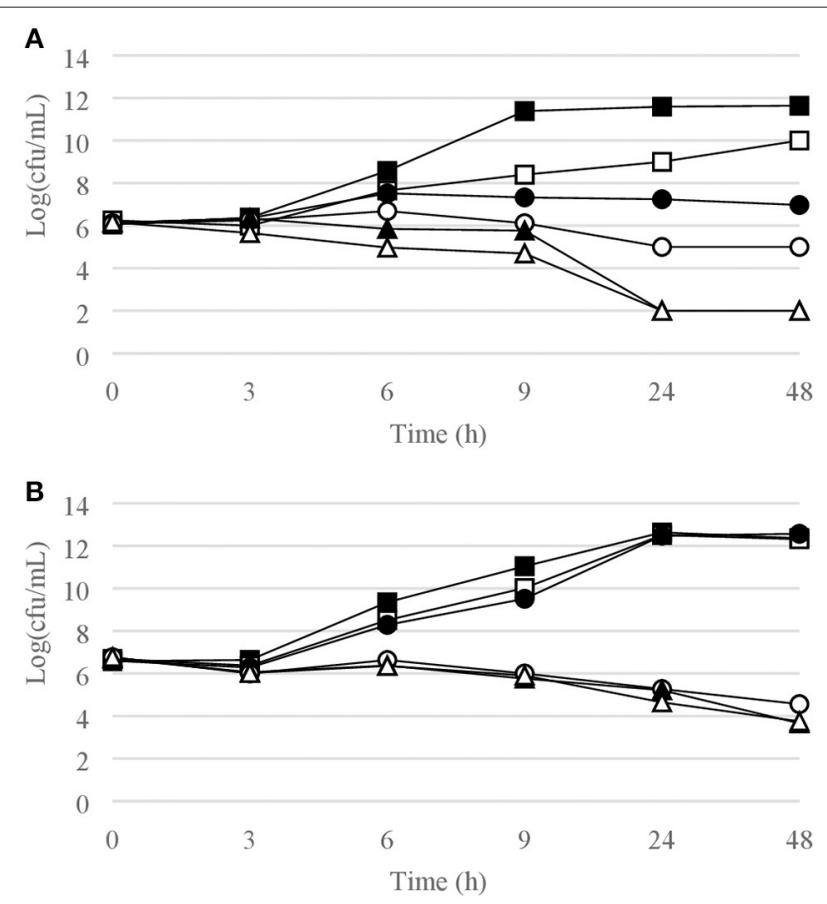

FIGURE 3 | Time-kill curves for (A) S. pyogenes, chlorquinaldol; (B) E. faecalis, chlorquinaldol. Filled square, control; open square, $1 / 4 \times$ MIC; filled circle, $1 / 2 \times$ MIC; open circle, $1 \times$ MIC; filled triangle, $2 \times$ MIC; open triangle, $4 \times$ MIC.

failure. In this background, alternative treatments for patients infected with bacteria resistant to conventional antimicrobials are urgently required. Some possibilities
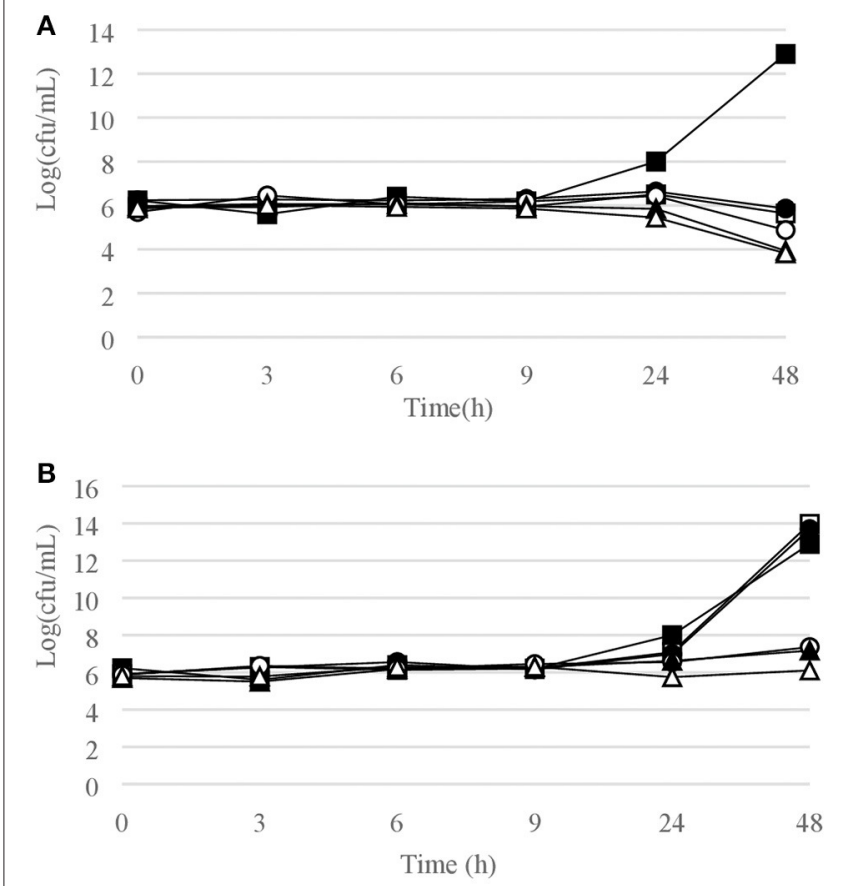

FIGURE 4 | Time-kill curves for $P$. acnes. (A) chlorquinaldol; (B) fusidic acid. Filled square, control; open square, $1 / 4 \times \mathrm{MIC}$; filled circle, $1 / 2 \times \mathrm{MIC}$; open circle, $1 \times$ MIC; filled triangle, $2 \times$ MIC; open triangle, $4 \times$ MIC.

comprise combination therapy or revival of older antimicrobial agents, for which resistance has not been developed yet. 

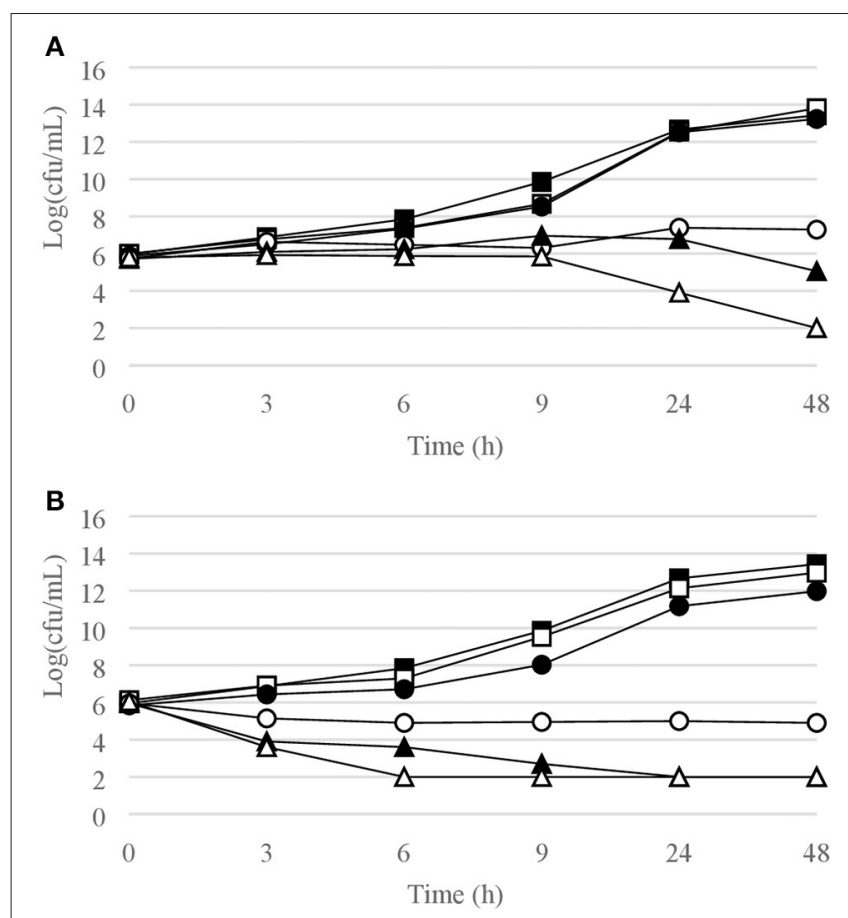

FIGURE 5 | Time-kill curves for $P$. aeruginosa. (A) chlorquinaldol; (B) gentamicin. Filled square, control; open square, $1 / 4 \times$ MIC; filled circle, $1 / 2 \times$ $\mathrm{MIC}$; open circle, $1 \times \mathrm{MIC}$; filled triangle, $2 \times \mathrm{MIC}$; open triangle, $4 \times \mathrm{MIC}$.

One of these old drugs is chlorquinaldol, which is generally administered as an ointment in association with topical corticosteroids (usually $1 \%$ chlorquinaldol plus $0.1 \%$ diflucortolone valerate) for the treatment of SSTIs. Its percutaneous absorption is very small, narrowing the risk of systemic effects (Degen et al., 1979). Few past studies showed its efficacy in vivo against various skin and soft tissue diseases of infectious nature (Maeder et al., 1983; Hoppe, 1988; Corrihons et al., 1991). Nevertheless, recent investigations re-evaluating its antimicrobial activity are lacking and its mechanism of action is not clear yet.

Chlorquinaldol is a bihalogenated derivative of 8hydroxyquinoline. Antimicrobial effects of 8-hydroxyquinoline and its derivatives, encompassing antibacterial, antimalarial, antiviral, antitubercular, and antiplaque activities have been previously reported (Prachayasittikul et al., 2013). It is assumed that they take advantage of their lipophilicity to penetrate bacterial cell membranes, where their antimicrobial action is probably related to chelating activities (Anjaneyulu et al., 1982; Hongmanee et al., 2007; Darby and Nathan, 2010). Metal ions play an important role in biological processes, and metal homeostasis is required for maintenance of cellular functions. Chelated metals become unavailable, inhibiting certain metabolic processes (Fraser and Creanor, 1975; Rohde et al., 1977; Chobot et al., 2011; Skrivanova et al., 2016). Until now, neither breakpoint nor pharmacodynamics data for chlorquinaldol, nor studies reporting MIC-values for a wide range of both Gram-positive and Gram-negative microorganisms are available.
In this context, it is difficult to define a spectrum of activity for chlorquinaldol.

In the present study, chlorquinaldol exerted growthinhibitory effects at different concentrations, depending on the species in exam. In particular, it seemed to be more effective against Gram-positive bacteria, especially staphylococci and enterococci, which are the most frequent microorganisms causing skin infections (Zlatkov et al., 1996; Lipsky et al., 2007).

Skrivanova et al. suggested that interspecies variability in the response to 8-hydroxyquinolines might be due to the different capacities of bacteria to accumulate metallic ions (Skrivanova et al., 2016). Hence, the role of metalloenzymes in different species should be explored to identify the mechanism of chlorquinaldol antibacterial action.

In this study, the most prominent effects exerted by chlorquinaldol were observed on staphylococci. In a past work, Mann et al. evaluated the antimicrobial activity of chlorquinaldol against 200 strains of $S$. aureus, reporting much higher MICvalues (6-100 $\mathrm{mg} / \mathrm{L})$ than those observed in the present manuscript (Mann et al., 1960). The reason for this discrepancy is unknown; we hypothesize that it may be due to less standardized methods respect to present international guidelines. In example, no informations about the inoculum are provided, nor about the manufacturer of chlorquinaldol, the exact formulation and the purity.

In the present work, inhibitory concentrations of chlorquinaldol were slightly higher than those of fusidic acid, but differently from this latter, activity of chlorquinaldol was mainly bactericidal. This activity was confirmed by the timekill curves: chlorquinaldol was bactericidal for both S. aureus and S. epidermidis, killing more than $99.9 \%$ of the initial inoculum at $48 \mathrm{~h}$ at $4 \times$ MIC concentrations, while fusidic acid displayed a classical bacteriostatic trend. Furthermore, five MRSE and one MSSA were resistant to fusidic acid while all MIC of the staphylococci tested for chlorquinaldol fell into a narrower range of action, always below a concentration of $0.5 \mathrm{mg} / \mathrm{L}$. These data are of particular interest because of the long time documented emergence of fusidic acid resistance associated with topical monotherapy, which is five times higher than in oral treatment (Turnidge and Collignon, 1999; Howden and Grayson, 2006; Heng et al., 2013; Williamson et al., 2014). Though gentamicin showed a bactericidal effect at a concentration of $2 \times \mathrm{MIC}$ at $24 \mathrm{~h}$ against the tested staphylococci, only $20 \%$ of tested strains resulted susceptible to gentamicin. Indeed, high percentages of gentamicin-resistance in staphylococci isolated from skin infections have been reported by other authors, and nosocomial outbreaks of gentamicin-resistant $S$. aureus associated with the use of topical gentamicin were described in the past (Bint et al., 1977; Wyatt et al., 1977; Graham et al., 1980; Moet et al., 2007; Iwaki et al., 2011; Caraciolo et al., 2012). Moreover, use of gentamicin impregnated collagen sponges has been recently associated to an increased probability of sternal wound infection after cardiac surgery caused by gentamicin-resistant bacteria (Rapetto et al., 2016). As shown by time-kill curves, chlorquinaldol was bactericidal also against E. faecalis and $S$. pyogenes, at concentration of $2 \times$ MIC, while no bactericidal effects were observed against $P$. acnes. All the tested $E$. faecalis 

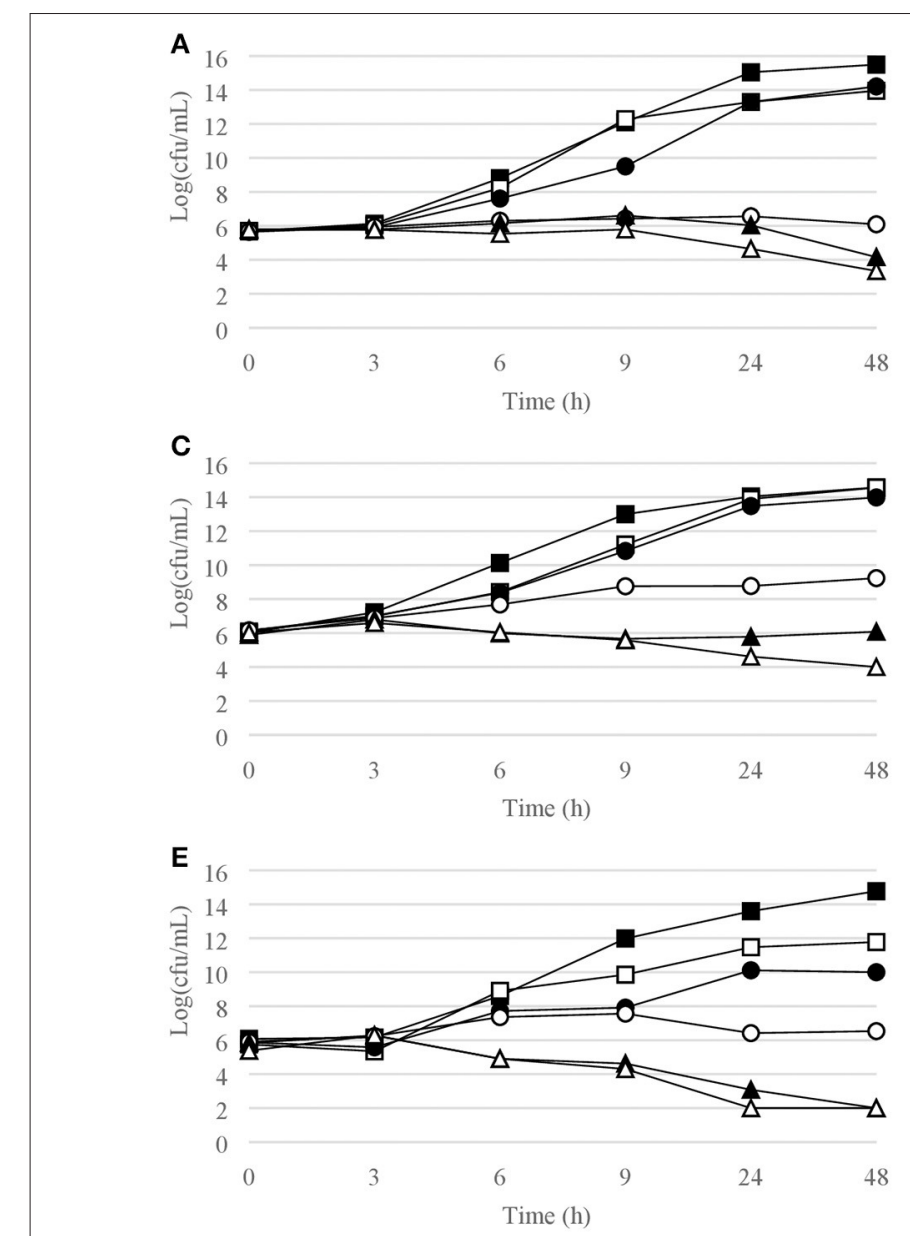

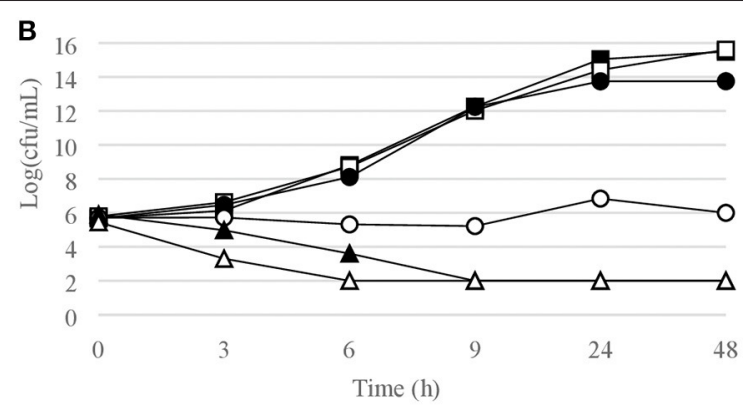

D

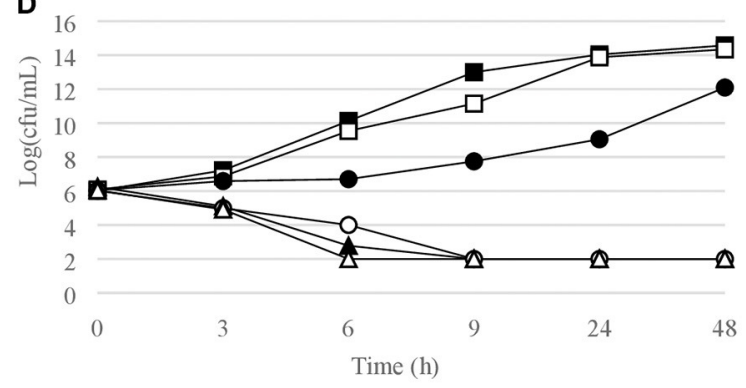

FIGURE 6 | Time-kill curves for enterobacteriaceae. (A) E. coli, chlorquinaldol; (B) E. coli, gentamicin; (C) E. cloacae, chlorquinaldol; (D) E. cloacae, gentamicin; (E) P. mirabilis, chlorquinaldol. Filled square, control; open square, $1 / 4 \times$ MIC; filled circle, $1 / 2 \times$ MIC; open circle, $1 \times$ MIC; filled triangle, $2 \times \mathrm{MIC}$; open triangle, $4 \times$ MIC.

strains were susceptible to chlorquinaldol at low concentrations, with an MBC-value equal or 2-fold the MIC-value. Considering the intrinsic resistance to gentamicin of this species and the poor activity of fusidic acid on our isolates, which is in line with literature review, chlorquinaldol can represent a valid choice to treat E. faecalis infections (Collignon and Turnidge, 1999).

Chlorquinaldol was effective against all the Gram-negative strains at high concentrations. We observed gentamicin resistance in more than $60 \%$ of the tested strains, which is higher than that observed in the SENTRY Antimicrobial Surveillance Program over a 7-year period (1998-2004) in SSTI (Moet et al., 2007).

Considering that, usually, topical formulations contain high concentrations of antibiotics, it may be hypothesized that chlorquinaldol levels at the infection site might be much higher than the MIC observed in this study.

In conclusion, chlorquinaldol, due to its wide spectrum of activity, would provide a valuable alternative for the treatment of SSTIs. Moreover, its use in combination with other antibiotics could be hypothesized in order to enhance antimicrobial activity and to limit the increasing resistance to topical antibiotics.
Further, studies aiming to define a clinical breakpoint, evaluate synergy with other compounds and the ability to select for resistance after antibiotic exposure are advisable in the next future. Old studies pointed out chlorquinaldol efficacy against mycotic infections, so additional investigations to update its spectrum of activity against fungi would be also of great interest.

\section{AUTHOR CONTRIBUTIONS}

LD conceived and designed the experiments. $\mathrm{MB}, \mathrm{AB}$, and $\mathrm{MA}$ performed the experiments. $\mathrm{MB}, \mathrm{AB}$, and $\mathrm{ED}$ analyzed the data. $\mathrm{MB}$ and $\mathrm{AB}$ prepared figures and graphs and wrote the manuscript. LD and ED revised the manuscript. All the authors read and approved the final manuscript.

\section{FUNDING}

This work was supported by Consorzio Milano Ricerche, Milan, Italy. The sponsor was not involved in study design, in the collection, analysis and interpretation of data, the writing of the report nor in the decision to submit the article for publication. 


\section{REFERENCES}

Anjaneyulu, Y., Rao, R. P., Swamy, R. Y., Eknath, A., and Narasimha Rao, K. (1982). In vitro antimicrobial-activity studies on the mixed ligand complexes of $\mathrm{Hg}$ (II) with 8-hydroxyquinoline and salicylic acids. Proc. Indian. Acad. Sci. (Chem. Sci.) 91, 157-163.

Bint, A. J., George, R. H., Healing, D. E., Wise, R., and Davies, M. (1977). An outbreak of infection caused by a gentamicin-resistant Staphylococcus aureus. J. Clin. Pathol. 30, 165-167. doi: 10.1136/jcp. 30.2.165

Bjarnsholt, T. (2013). The role of bacterial biofilms in chronic infections. APMIS. Suppl 136, 1-58. doi: 10.1111/apm.12099

Bonamonte, D., Belloni Fortina, A., Neri, L., and Patrizi, A. (2014). Fusidic acid in skin infections and infected atopic eczema. G. Ital. Dermatol. Venereol. 149, 453-459.

Caraciolo, F. B., Maciel, M. A., Santos, J. B., Rabelo, M. A., and Magalhães, V. (2012). Antimicrobial resistance profile of Staphylococcus aureus isolates obtained from skin and soft tissue infections of outpatients from a university hospital in Recife-PE, Brazil. An. Bras. Dermatol. 87, 857-861. doi: 10.1590/S0365-05962012000600006

Cardona, A. F., and Wilson, S. E. (2015). Skin and soft-tissue infections: a critical review and the role of telavancin in their treatment. Clin. Infect. Dis. 61(Suppl. 2), 69-78. doi: 10.1093/cid/civ528

Chobot, V., Drage, S., and Hadacek, F. (2011). Redox properties of 8quinolinol and implications for its mode of action. Nat. Prod. Commun. 6, 597-602.

Collignon, P., and Turnidge, J. (1999). Fusidic acid in vitro activity. Int. J. Antimicrob. Agents 12(Suppl. 2), 45-58. doi: 10.1016/S0924-8579(98) 00073-9

Corrihons, I., Dutilh, B., and Bébéar, C. (1991). In vitro activity of an antiseptic, chlorquinaldol, against Neisseria gonorrhoeae and Chlamydia trachomatis. Pathol. Biol. 39, 136-139.

Darby, C. M., and Nathan, C. F. (2010). Killing of non-replicating Mycobacterium tuberculosis by 8-hydroxyquinoline. J. Antimicrob. Chemother. 65, 1424-1427. doi: $10.1093 /$ jac/dkq145

Degen, P. H., Moppert, J., Schmid, K., and Weirich, E. G. (1979). Percutaneous absorption of chlorquinaldol (Sterosan). Dermatologica 159, 239-244. doi: 10.1159/000250600

Esposito, S., Bassetti, M., Bonnet, E., Bouza, E., Chan, M., De Simone, G., et al. (2016). Hot topics in the diagnosis and management of skin and soft-tissue infections. Int. J. Antimicrob. Agents 48, 19-26. doi: 10.1016/j.ijantimicag.2016.04.011

Fraser, R. S., and Creanor, J. (1975). The mechanism of inhibition of ribonucleic acid synthesis by 8 -hydroxyquinoline and the antibiotic lomofungin. Biochem. J. 147, 401-410. doi: 10.1042/bj1470401

Graham, D. R., Correa-Villasenor, A., Anderson, R. L., Vollman, J. H., and Baine, W. B. (1980). Epidemic neonatal gentamicin-methicillin-resistant Staphylococcus aureus infection associated with nonspecific topical use of gentamicin. J. Pediatr. 97, 972-978. doi: 10.1016/S0022-3476(80) 80439-2

Heng, Y. K., Tan, K. T., Sen, P., Chow, A., Leo, Y. S., Lye, D. C., et al. (2013). Staphylococcus aureus and topical fusidic acid use: results of a clinical audit on antimicrobial resistance. Int. J. Dermatol. 52, 876-881. doi: 10.1111/j.1365-4632.2012.05747.x

Hongmanee, P., Rukseree, K., Buabut, B., Somsri, B., and Palittapongarnpim, P. (2007). In vitro activities of cloxyquin (5-chloroquinolin-8-ol) against Mycobacterium tuberculosis. Antimicrob. Agents Chemother. 51, 1105-1106. doi: 10.1128/AAC.01310-06

Hoppe, G. (1988). Diflucortolone valerate. Asian experience. Drugs 36(Suppl. 5), 24-33. doi: 10.2165/00003495-198800365-00006

Howden, B. P., and Grayson, M. L. (2006). Dumb and dumber-the potential waste of a useful antistaphylococcal agent: emerging fusidic acid resistance in Staphylococcus aureus. Clin. Infect. Dis. 42, 394-400. doi: 10.1086/4 99365

Iwaki, M., Noguchi, N., Nakaminami, H., Sasatsu, M., and Ito, M. (2011). Antimicrobial activity and frequency of spontaneous gentamicin-resistant mutants in bacteria related skin infections. Yakugaku Zasshi 131, 1653-1659. doi: 10.1248/yakushi.131.1653

Kolev, K. K., Vŭrbanova, S., Chervenkov, S., and Pavlov, A. (1987). Antibacterial activity of chlorquinaldol esters and 2-styryl-substituted derivatives. Vet. Med. Nauki. 24, 81-87.

Lipsky, B. A., Weigelt, J. A., Gupta, V., Killian, A., and Peng, M. M. (2007). Skin, soft tissue, bone, and joint infections in hospitalized patients: epidemiology and microbiological, clinical, and economic outcomes. Infect. Control. Hosp. Epidemiol. 28, 1290-1298. doi: 10.1086/520743

Littman, M. L. (1955). Antimycotic effect of chlorquinaldol. Trans. N.Y. Acad. Sci. 18, 161-174. doi: 10.1111/j.2164-0947.1955.tb00431.x

Maeder, E., Schindléry, C., Macarol, V., and Schoenenberger, P. M. (1983). A comparative multicentre trial of halometasone/triclosan cream and diflucortolone valerate/chlorquinaldol cream in the treatment of acute dermatomycoses. J. Int. Med. Res. 11(Suppl. 1), 48-52.

Mann, P. H., Fratta, I., and Sigg, E. B. (1960). Susceptibility testing of 200 strains of Staphylococcus aureus to chlorquinaldol. Antibiot. Chemother. 10, $771-772$.

Meyer-Rohn, J., and Puschmann, M. (1980). In vitro demonstration of the antibacterial and antimycotic efficacy of a preparation containing nystatin and chlorquinaldol compared with similar antimicrobial agents. Mykosen 23, 320-324. doi: 10.1111/j.1439-0507.1980.tb0 2614.x

Moet, G. J., Jones, R. N., Biedenbach, D. J., Stilwell, M. G., and Fritsche, T. R. (2007). Contemporary causes of skin and soft tissue infections in North America, Latin America, and Europe: report from the SENTRY Antimicrobial Surveillance Program (1998-2004). Diagn. Microbiol. Infect. Dis. 57, 7-13. doi: 10.1016/j.diagmicrobio.2006.05.009

Prachayasittikul, V., Prachayasittikul, S., Ruchirawat, S., and Prachayasittikul, V. (2013). 8-Hydroxyquinolines: a review of their metal chelating properties and medicinal applications. Drug. Des. Devel. Ther. 7, 1157-1178. doi: $10.2147 / D D D T . S 49763$

Rapetto, F., Bruno, V. D., Guida, G., Marsico, R., Chivasso, P., and Zebele, C. (2016). Gentamicin-impregnated collagen sponge: effectiveness in preventing sternal wound infection in high-risk cardiac surgery. Drug Target Insights 10(Suppl. 1), 9-13. doi: 10.4137/DTI.S39077

Ray, G. T., Suaya, J. A., and Baxter, R. (2013). Incidence, microbiology, and patient characteristics of skin and soft-tissue infections in a U.S. population: a retrospective population-based study. BMC Infect. Dis. 13:252. doi: 10.1186/1471-2334-13-252

Regös, J., Zak, O., Solf, R., Vischer, W. A., and Weirich, E. G. (1979) Antimicrobial spectrum of triclosan, a broad-spectrum antimicrobial agent for topical application. II. Comparison with some other antimicrobial agents. Dermatologica 158, 72-79.

Robinson, H. M. Jr., and Hollander, M. B. (1956). Topical use of chlorquinaldol. J. Invest. Dermatol. 26, 143-147. doi: 10.1038/jid.1956.19

Rohde, W., Cordell, B., Webster, R., and Levinson, W. (1977). Inhibition of amino acyl tRNA synthetase activity by copper complexes of two metal binding ligands. N-Methyl isatin beta-thiosemicarbazone and 8-hydroxyquinoline. Biochim. Biophys. Acta 477, 102-111. doi: 10.1016/0005-2787(77) 90226-X

Sikorski, R., Hencner, Z., Gliński, Z., Wawrzkiewicz, K., Radomański, T., Milart, P., et al. (1992). Microbiological evaluation of the effectiveness of gynalgin in the treatment of vaginitis. Wiad. Lek. 45, 263-269.

Skrivanova, E., Van Immerseel, F., Hovorkova, P., and Kokoska, L. (2016). In Vitro selective growth-inhibitory effect of 8-Hydroxyquinoline on Clostridium perfringens versus Bifidobacteria in a medium containing chicken ileal digesta. PLoS ONE 11:e0167638. doi: 10.1371/journal.pone.01 67638

Turnidge, J., and Collignon, P. (1999). Resistance to fusidic acid. Int. J. Antimicrob. Agents 12(Suppl. 2), 35-44. doi: 10.1016/S0924-8579(98) 00072-7

van Koppen, C. J., and Hartmann, R. W. (2015). Advances in the treatment of chronic wounds: a patent review. Expert. Opin. Ther. Pat. 25, 931-937. doi: $10.1517 / 13543776.2015 .1045879$ 
Williamson, D. A., Monecke, S., Heffernan, H., Ritchie, S. R., Roberts, S. A., Upton, A., et al. (2014). High usage of topical fusidic acid and rapid clonal expansion of fusidic acid-resistant Staphylococcus aureus: a cautionary tale. Clin. Infect. Dis. 59, 1451-1454. doi: 10.1093/cid/ciu658

Wyatt, T. D., Ferguson, W. P., Wilson, T. S., and McCormick, E. (1977). Gentamicin resistant Staphylococcus aureus associated with the use of topical gentamicin. J. Antimicrob. Chemother. 3, 213-217. doi: 10.1093/jac/ 3.3.213

Zlatkov, V., Shopova, E., Marinova, B., and Katsarova, M. (1996). The therapeutic potentials of the vaginal antimicrobial preparation Chlorchinaldin. Akush Ginekol (Sofiia) 35, 49-50.
Conflict of Interest Statement: The authors declare that the research was conducted in the absence of any commercial or financial relationships that could be construed as a potential conflict of interest.

Copyright (c) 2017 Bortolin, Bidossi, De Vecchi, Avveniente and Drago. This is an open-access article distributed under the terms of the Creative Commons Attribution License (CC BY). The use, distribution or reproduction in other forums is permitted, provided the original author(s) or licensor are credited and that the original publication in this journal is cited, in accordance with accepted academic practice. No use, distribution or reproduction is permitted which does not comply with these terms. 